\title{
Techno-economic analysis of combining forward osmosis-reverse osmosis and anaerobic membrane bioreactor technologies for municipal wastewater treatment and water production
}

\author{
Sergi Vinardell ${ }^{\mathrm{a}, *}$, Sergi Astals ${ }^{\mathrm{a}}$, Joan Mata-Alvarez ${ }^{\mathrm{a}}$, Joan Dosta $^{\mathrm{a}}$ \\ a Department of Chemical Engineering and Analytical Chemistry, University of \\ Barcelona, 08028, Barcelona, Spain \\ *Corresponding author (e-mail: svinardell@ub.edu)
}

\begin{abstract}
The economic feasibility of combining forward osmosis (FO), reverse osmosis (RO) and anaerobic membrane bioreactor (AnMBR) technologies for municipal wastewater treatment with energy and water production was analysed. FO was used to preconcentrate the AnMBR influent, RO for draw solution regeneration and water production, and AnMBR for wastewater treatment and energy production. The minimum wastewater treatment cost was estimated at $0.81 € \mathrm{~m}^{-3}$, achieved when limiting the FO recovery to $50 \%$ in a closed-loop scheme, however, the cost increased to 1.01 and $1.27 €$ $\mathrm{m}^{-3}$ for FO recoveries of $80 \%$ and $90 \%$, respectively. The fresh water production cost was estimated at 0.80 and $1.16 € \mathrm{~m}^{-3}$ for an open-loop scheme maximising water production and a closed-loop scheme, respectively. The low FO membrane fluxes were identified as a limiting factor and a sensitivity analysis revealed that FO membrane fluxes of $10 \mathrm{LMH}$ would significantly improve the competitiveness of FO-RO+AnMBR technology.
\end{abstract}

KEYWORDS: Anaerobic digestion; Anaerobic membrane bioreactor (AnMBR); Forward Osmosis (FO); Reverse Osmosis (RO); Municipal sewage treatment 


\section{Introduction}

Wastewater treatment plants (WWTPs) based on the conventional activated sludge (CAS) process are not suitable to meet the environmental and economic requirements of the circular biobased economy since they are designed to remove resources rather than recovering them (Guest et al., 2009). Accordingly, new WWTP technologies and configurations have arisen to maximize resources harvesting and support the transition of WWTPs towards the concept of wastewater resource recovery facilities (WRRF) (Puyol et al., 2017).

Anaerobic membrane bioreactor (AnMBR) technology is attracting attention as a mainstream process for municipal wastewater treatment due to its capacity to recover most of the energy potential in wastewater and produce high-quality effluents (McCarty et al., 2011; Puyol et al., 2017). Anaerobic digestion allows to recover the energy content of municipal sewage by transforming its biodegradable organic matter into renewable methane energy. Another noteworthy feature of AnMBR is the high retention of particles provided by the membrane which allows an excellent decoupling of the hydraulic retention time (HRT) from the solids retention time (SRT). This provides a high controllability on the active biomass concentration in the reactor (Maaz et al., 2019).

However, the economic feasibility of AnMBR technology is limited by the low concentration of organics in municipal sewage and the associated high capital (e.g. higher vessel volume, additional membrane modules) and operational (e.g. gas sparging, biomass recirculation) costs. One option to overcome this limitation is the preconcentration of sewage by means of forward osmosis (FO) (Ansari et al., 2017). The FO process concentrates the total solids contained in sewage by permeating water towards a draw solution using a selective membrane (Cath et al., 2006). The draw solution is a 
natural (e.g. seawater) or artificial solution (e.g. $\mathrm{NaCl}, \mathrm{MgCl}_{2}$ ) that generates an osmotic gradient (driving force) between both solutions (Itliong et al., 2019; Lee and Hsieh, 2019). Consequently, water flows spontaneously from the sewage to the draw solution through a dense semipermeable membrane: (i) decreasing the sewage flow and increasing the organics concentration and (ii) increasing the draw solution flow and diluting the solute concentration. The concentration of sewage prior to an AnMBR reduces the volumetric flow and, in turn, the volume of the anaerobic reactor (Ansari et al., 2017; Ferrari et al., 2019). Additionally, if a draw solution regeneration step is implemented, it is possible to produce clean water while re-concentrating the diluted draw solution.

Reverse osmosis (RO) stands as the most used technology to produce clean water from diluted draw solutions (Awad et al., 2019; Luo et al., 2014). The combination of FO and RO is particularly interesting for open-loop seawater desalination schemes (once-through systems), where seawater is used as a draw solution and, subsequently, clean water is produced by RO from the diluted seawater (Blandin et al., 2016; Jalab et al., 2019). It is worth to mention that FO-RO system is not thermodynamically favourable when compared to sewage direct RO due to the higher osmotic pressure of the diluted seawater in comparison to municipal sewage (Shaffer et al., 2015). However, the FO-RO system offers important advantages such as a dual barrier to the pollutants and a lower fouling potential in the RO membranes (Blandin et al., 2016). Furthermore, due to its lower osmotic potential, less energy is required to produce clean water from the diluted seawater than from conventional seawater (Hancock et al., 2012; Wan and Chung, 2018).

Several publications have stated that the FO-RO system is a more profitable scenario for seawater desalination than the stand-alone RO system (Cath et al., 2010; Valladares Linares et al., 2016; Wan and Chung, 2018). However, other publications have pointed 
out that the low FO fluxes and the high FO membrane prices are important limitations for the implementation of such system (Awad et al., 2019; Blandin et al., 2015; Lee and Hsieh, 2019). Regarding FO fluxes, Blandin et al. (2015) reported that an average flux of $30 \mathrm{~L} \mathrm{~m}^{-2} \mathrm{~h}^{-1}(\mathrm{LMH})$ is needed to guarantee the economic suitability of an FO-RO system for seawater desalination. However, a $30 \mathrm{LMH}$ flux is far from current FO fluxes since reported pilot-scale fluxes range from 2.2 to 10.6 LMH (Awad et al., 2019).

There are evident differences among the published articles regarding the technoeconomic feasibility of FO-RO systems. These differences can be related to discrepancies in operational conditions, capital and operational costs, assumptions and omission of some parameters. For instance, the impact of FO recovery and RO strategies for draw solution regeneration and water production have been rarely included in previous studies. To the best of the authors' knowledge, the impact of FO as a pre-concentration step of an AnMBR has not been previously analysed from a techno-economic point of view. Therefore, a detailed and comprehensive techno-economic analysis is needed to determine in which scenarios the combination of FO, RO and AnMBR is economically and technically attractive as well as to identify the process limiting factors.

The goal of this study is to analyse the economic feasibility of a system combining FO for sewage pre-concentration, RO for clean water production and AnMBR for renewable energy production. This theoretical techno-economic analysis includes the impact of different FO recoveries, different draw solution management strategies and the implication of these factors on the AnMBR design. The ultimate goal is to provide a comprehensive tool that allows to evaluate in which scenarios the combination of FO, RO and AnMBR technology is recommendable from both economic and technical points of view. 


\section{Methodology}

\subsection{Evaluated wastewater treatment scenarios and design criteria}

The economic feasibility of an AnMBR system for mainstream sewage treatment was evaluated for four different scenarios (Table 1). The baseline scenario was the implementation of an AnMBR without FO for sewage pre-concentration nor RO for water production. The other three scenarios resulted from assessing three different FO recoveries, i.e. (i) 50\% recovery (Scenario 1), (ii) 80\% recovery (Scenario 2), and (iii) 90\% recovery (Scenario 3). The FO recovery is an important parameter since it determines (i) the flow rate and concentration of the AnMBR influent and (ii) the flow rate and osmotic pressure of the diluted draw solution feeding the RO stage. Previous economic studies considered FO recoveries around 50\% (Blandin et al., 2015; Valladares Linares et al., 2016). However, in this study, the three different recovery scenarios (i.e. $50,80$ and $90 \%)$ were selected since (i) high FO recoveries $(\geq 50 \%)$ can enhance the operability and applicability of AnMBR technology and (ii) FO recoveries up to $90 \%$ have been achieved for municipal wastewater pre-concentration (Ansari et al., 2018).

For each FO recovery scenario, the FO-RO+AnMBR process was assessed for three different draw solution management schemes (Table 1). The three different schemes are as follow (Figure 1):

- Scheme A: Open-loop system aiming to maximize water production in the RO stage. In this scenario, water production (i.e. RO recovery) from the diluted seawater is determined by permeating the amount of water needed to reach a brine osmotic pressure of 46.7 bar. This is a typical brine osmotic pressure in conventional seawater desalination featuring an RO recovery of $45 \%$. 
- Scheme B: Open-loop system where water production in the RO stage is limited by fixing the RO recovery at $45 \%$ regardless of the diluted seawater osmotic pressure. $\mathrm{RO}$ recovery is fixed at $45 \%$ since this is a common value in full-scale desalination plants (Blandin et al., 2016).

- Scheme C: Closed-loop system where the RO stage is used to re-establish the osmotic pressure of the synthetic draw solution. In this system, RO recovery is fixed by FO performance since the amount of water extracted in the RO stage is the same that permeated the $\mathrm{FO}$ membrane. $\mathrm{NaCl}$ was the solute in the synthetic draw solution.

Open-loop systems are preferred in regions where seawater is available (Blandin et al., 2016). An open-loop is a once-through system where the brine (concentrated seawater) from the RO stage is directly discharged to the sea/ocean. Open-loop schemes provide higher flexibility in RO recoveries since the regenerated seawater does not need to be reused. Another conceivable open-loop scenario would be to directly discharge diluted seawater from the FO stage into the sea/ocean. However, this scenario would only consider FO+AnMBR in coastal areas and would fail to recover the filtered water. Accordingly, this scheme was not included in this publication. On the other hand, closedloop schemes using synthetic draw solutions are required in non-coastal areas.

This FO-RO+AnMBR process was evaluated for a medium-sized facility (i.e. 30,000 population equivalent (PE)) treating $148 \mathrm{~L} \mathrm{PE}^{-1} \mathrm{day}^{-1}$ of an average strength municipal sewage $\left(\mathrm{COD}_{\mathrm{T}}=420 \mathrm{mg} \mathrm{COD} \mathrm{L}^{-1} ; \mathrm{COD}_{\mathrm{S}}=300 \mathrm{mg} \mathrm{COD} \mathrm{L}^{-1} ; \mathrm{COD}_{\mathrm{S}, \text { inert }}=30 \mathrm{mg} \mathrm{COD} \mathrm{L}^{-}\right.$ 1. $\left.\mathrm{COD}_{\text {particulate,inert }}=40 \mathrm{mg} \mathrm{COD} \mathrm{L}^{-1}\right)($ Garrido-Baserba et al., 2018). An average seawater composition with an osmotic pressure of 25.7 bar was considered $\left(\mathrm{Na}^{+}=10,900 \mathrm{mg} \mathrm{L}^{-1}\right.$; $\mathrm{Cl}^{-}=19,700 \mathrm{mg} \mathrm{L}^{-1} ; \mathrm{SO}_{4}{ }^{2-}=2,740 \mathrm{mg} \mathrm{L}^{-1} ; \mathrm{Mg}^{2+}=1,310 \mathrm{mg} \mathrm{L}^{-1} ; \mathrm{Ca}^{2+}=410 \mathrm{mg} \mathrm{L}^{-1} ; \mathrm{K}^{+}=$ $\left.390 \mathrm{mg} \mathrm{L}^{-1} ; \mathrm{HCO}_{3}^{-}=152 \mathrm{mg} \mathrm{L}^{-1}\right)$. 


\subsection{FO-RO process design and costs}

\subsubsection{Design considerations}

FO flux is governed by the osmotic gradient between the sewage and the draw solution. The solution-diffusion model is the most used model to describe water flux across dense FO membranes (Deshmukh et al., 2015; Kim et al., 2017). However, to accurately determine the FO flux, it is important to consider the effective osmotic gradient rather than the simple osmotic gradient. Thus, FO flux calculation needs to include (i) concentrative external concentration polarisation (ECP) on the active layer, (ii) concentrative internal concentration polarisation (ICP) on the support layer, and (iii) reverse salt diffusivity from draw solution to sewage solution (Eq. 1) (Blandin et al., 2015; Kim et al., 2017). Eq. 1 describes the FO flux when the active layer is facing the feed side. This strategy exacerbates ICP on the support layer, however, it reduces fouling and, therefore, it is the preferred in the long term operation (Blandin et al., 2015).

$J_{W}=A \cdot\left[\frac{\pi_{\text {Dbulk }} \cdot e^{-J_{W} \cdot \frac{S}{D}}-\pi_{F b u l k} \cdot e^{\frac{J_{W}}{k}}}{1-\frac{B}{J_{W}} \cdot\left(e^{-J_{w} \cdot \frac{S}{D}}-e^{\frac{J_{W}}{k}}\right)}\right]$

Where $J_{\mathrm{w}}$ is the water flux $\left(\mathrm{L} \mathrm{m}^{-2} \mathrm{~h}^{-1}\right), \Pi_{\mathrm{D} \text {, bulk }}$ is the osmotic pressure in the draw solution side (bar), $\Pi_{\mathrm{F}, \text { bulk }}$ is the osmotic pressure in the sewage side (bar), $\mathrm{k}$ is the mass transfer coefficient $\left(38.52 \mathrm{~L} \mathrm{~m}^{-2} \mathrm{~h}^{-1}\right), \mathrm{D}$ is the solute self-diffusion coefficient $\left(5.33 \times 10^{-3} \mathrm{~L} \mathrm{~m}^{-1} \mathrm{~h}^{-}\right.$ $\left.{ }^{1}\right), \mathrm{S}$ is the structural parameter $\left(6.9 \times 10^{-4} \mathrm{~m}\right), \mathrm{A}$ is the pure water permeability $\left(1.63 \mathrm{~L} \mathrm{~m}^{-}\right.$ ${ }^{2} \mathrm{~h}^{-1}$ bar $\left.^{-1}\right)$, and $\mathrm{B}$ is the salt permeability $\left(0.2988 \mathrm{~L} \mathrm{~m}^{-2} \mathrm{~h}^{-1}\right)$ (Blandin et al., 2015). Regarding RO flux, an average flux of $15 \mathrm{LMH}$ was considered according to literature (Valladares Linares et al., 2016; Teusner et al., 2017). 


\subsubsection{FO-RO capital costs}

The methodology used to calculate the capital expenditures (CAPEX) of the FO-RO process was adapted from Blandin et al. (2015). Due to the limited data on FO costs some assumptions based on RO values were necessary. The Scenario 1A was taken as a benchmark of this study since this scenario presented similar areas for both FO and RO membranes and, consequently, a more reliable estimation of FO CAPEX could be achieved.

CAPEX costs were split in costs directly depending on the surface area of RO unit (e.g. membranes, pressure vessels) and costs independent of the RO unit surface area (e.g. pretreatment, intake/outfall). The independent costs were considered constant in all the scenarios. This approach made the CAPEX associated with the RO stage just a function of the membrane area. The CAPEX calculations for the FO stage were similar to the ones used for the RO stage. However, some devices such as pressure vessels and pressure exchangers were excluded from the FO CAPEX calculations. Price differences between the FO and RO membrane modules were considered. The lower packing density of FO modules makes FO modules more expensive than RO modules (Blandin et al., 2015). In this study, RO and FO modules were considered to have a cost of 24 and $55 \$ \mathrm{~m}^{-2}$, respectively (Teusner et al., 2017; Valladares Linares et al., 2016).

\subsubsection{FO-RO operating costs}

Energy consumption, membrane replacement, labour, maintenance, chemical reagent consumption and draw solution replenishment were considered as operating expenditures (OPEX).

Energy costs accounted for the energy consumption for: (i) seawater and wastewater pretreatment, (ii) FO stage, and (iii) RO stage. Although the RO stage is the main energy 
consumer, to accurately determine the overall energy consumption it is important to include the other two processes (Choi et al., 2017). Pumping energy requirements for seawater pre-treatment were calculated using Eq. 2 (Wan and Chung, 2018).

$\mathrm{E}_{\mathrm{SWP}}=\frac{\Delta \mathrm{P}_{\mathrm{SWP}} \mathrm{Q}_{\mathrm{SW}}}{36 \eta_{\mathrm{P}}}$

Where $\mathrm{E}_{\mathrm{SWP}}$ is the energy consumption $(\mathrm{kW}), \Delta \mathrm{P}_{\mathrm{SWP}}$ is the pressure difference (bar), $\mathrm{Q}_{\mathrm{SW}}$ is the seawater influent flow rate $\left(\mathrm{m}^{3} \mathrm{~h}^{-1}\right)$, and $\eta_{\mathrm{p}}$ is the pump efficiency $(85 \%)$.

The energy consumption of the FO stage was considered $0.3875 \mathrm{kWh} \mathrm{m}^{-3}$ which is the average energy consumption value reported for FO pilot-scale plants (Awad et al., 2019). The energy consumption for the RO stage was estimated using the Reverse Osmosis System Analysis (ROSA) software (Filmtec Corporation, US). Energy recovery devices (ERDs) were considered for recovering the energy from the RO brine. The energy recovered was calculated by using Eq. 3 (Wan and Chung, 2018).

$\mathrm{E}_{\mathrm{ERD}}=\frac{\Delta \mathrm{P}_{\mathrm{ERD}} \mathrm{Q}_{\mathrm{ERD}} \eta_{\mathrm{ERD}}}{36}$

Where $\mathrm{E}_{\mathrm{ERD}}$ is the energy recovered by the device $(\mathrm{kW}), \Delta \mathrm{P}_{\mathrm{ERD}}$ is the pressure difference (bar), QERD is the flowrate feeding the device $\left(\mathrm{m}^{3} \mathrm{~h}^{-1}\right)$, and $\eta_{\text {ERD }}$ is the efficiency of the ERD $(95 \%)$.

Draw solution replenishment costs were considered for Scheme C (closed-loop scheme) to account for solute losses due to retro-diffusion flux $\left(\mathrm{J}_{\mathrm{S}}\right)$ from draw solution to sewage in the FO stage and the diffusion flux from the diluted draw solution to the permeate in the RO stage. JS was calculated using Eq. 4 (Kim et al., 2017; Tiraferri et al., 2013), while the solute diffusion in the $\mathrm{RO}$ stage was calculated from the final $\mathrm{NaCl}$ concentration in the permeate given by the ROSA software.

$J_{S}=B \cdot\left[\frac{c_{D} \cdot e^{-J_{W} \cdot \frac{S}{D}-c_{F} \cdot e^{\frac{J_{W}}{k}}}}{1+\frac{B}{J_{W}} \cdot\left(e^{\frac{J_{W}}{k}}-e^{-J_{W} \cdot \frac{S}{D}}\right)}\right]$ 
Where, besides the parameters described for Eq. $1, \mathrm{~J}_{\mathrm{S}}$ is the reverse-solute flux $\left(\mathrm{g} \mathrm{m}^{-2} \mathrm{~h}^{-1}\right)$, $\mathrm{c}_{\mathrm{D}}$ is the solute concentration in the draw solution $\left(\mathrm{g} \mathrm{L}^{-1}\right)$, and $\mathrm{c}_{\mathrm{F}}$ is the solute concentration in the feed solution $\left(\mathrm{g} \mathrm{L}^{-1}\right)$.

\subsection{AnMBR design and costs}

\subsubsection{Design considerations}

The AnMBR was designed for psychrophilic conditions $\left(20{ }^{\circ} \mathrm{C}\right)$. The selected configuration was submerged membranes since this configuration is commonly used for AnMBRs treating municipal sewage (Shin and Bae, 2018). A two-stage scheme consisting of a bioreactor and a separate membrane tank was used owing to the simpler membrane maintenance in comparison to a single-stage scheme. In this configuration, part of the generated biogas is recirculated for membrane scouring and fouling control. A specific gas sparging demand (SGD) of $0.23 \mathrm{Nm}^{3} \mathrm{~m}^{-2} \mathrm{~h}^{-1}$ was assumed (Giménez et al., 2011; Smith et al., 2014). For the ultrafiltration membrane area calculation, a net flux of 10 LMH was established (Giménez et al., 2011; Robles et al., 2013; Ruigómez et al., 2016; Smith et al., 2014).

The AnMBR was designed at a hydraulic retention time (HRT) of 1 day, and a solids retention time (SRT) of 60 days (Cashman et al., 2018; Hu and Stuckey, 2007; Prieto et al., 2013). Mixed liquor suspended solids (MLSS) concentration in the bioreactor was calculated according to Eq. 5 (Smith et al., 2014).

$\mathrm{X}_{\mathrm{M}}=\frac{\mathrm{SRT}}{\mathrm{HRT}} \cdot\left[\mathrm{X}_{\mathrm{I}}+\frac{\left(1+\mathrm{f}_{\mathrm{D}} \cdot \mathrm{k}_{\mathrm{d}} \cdot \mathrm{SRT}\right) \cdot \mathrm{Y} \cdot\left(\mathrm{S}_{\mathrm{S}, 0}-\mathrm{S}_{\mathrm{S}}\right)}{1+\mathrm{k}_{\mathrm{d}} \cdot S R T}\right]$

Where $\mathrm{X}_{\mathrm{M}}$ is the MLSS concentration (mg TSS L ${ }^{-1}$ ), SRT is the solids retention time (days), HRT is the hydraulic retention time (days), $\mathrm{X}_{\mathrm{I}}$ is the inert solids concentration in the influent $\left(\mathrm{mg} \mathrm{L}^{-1}\right), \mathrm{S}_{\mathrm{S}, 0}$ is the influent soluble organic matter $\left(\mathrm{mg} \mathrm{COD} \mathrm{L}^{-1}\right), \mathrm{S}_{\mathrm{S}}$ is the effluent soluble organic matter $\left(\mathrm{mg} \mathrm{COD} \mathrm{L}^{-1}\right), \mathrm{f}_{\mathrm{D}}$ is the decay coefficient $(0.20 \mathrm{mg}$ TSS 
$\left.\mathrm{mg} \mathrm{TSS}^{-1}\right), \mathrm{k}_{\mathrm{d}}$ is the decay rate $\left(0.02\right.$ day $\left.^{-1}\right)$ and $\mathrm{Y}$ is the yield $(0.076 \mathrm{mg}$ TSS $\left.\mathrm{mg} \mathrm{COD}^{-1}\right)$.

Influent pre-concentration increases the concentration of biodegradable COD and inert COD in the AnMBR influent which, if improperly managed, can lead to the accumulation of inert particles in the membrane tank. Therefore, the recirculation flow from the bioreactor to the membrane tank is important to maintain a low solids concentration in the membrane tank and minimize membrane fouling (Ferrer et al., 2015). To determine this flow, a maximum MLSS concentration of $18 \mathrm{~g} \mathrm{~L}^{-1}$ was established for the membrane tank (Martinez-Sosa et al., 2011; Shin and Bae, 2018). However, in Scenario 3 (i.e., 90\% pre-concentration) this threshold solids concentration was surpassed owing to the high concentration of inert particles in the influent. To reduce the solids concentration in the membrane tank and associated fouling, an HRT of 2 days was considered in Scenario 3.

\subsubsection{AnMBR capital and operating costs}

The MBR CAPEX accounts for civil engineering, mechanical and electrical, equipment and land costs (Judd, 2017). However, since the land cost is very site-specific it was excluded in this study. On the other hand, the OPEX analysis of the AnMBR included energy demand, sludge handling, membrane replacement, chemical reagents for membrane cleaning, equipment maintenance and replacement, and labour.

Energy consumption was considered for: (i) pumping and stirring, (iii) gas sparging, and (iii) centrifuge sludge dewatering. The energy consumption for stirring was assumed to be $8 \mathrm{~W} \mathrm{~m}^{-3}$ (Smith et al., 2014). The energy consumption of the centrifugal pumps was calculated using Eq. 6 (Wan and Chung, 2018).

$\mathrm{E}_{\mathrm{P}}=\frac{\Delta \mathrm{P}_{\mathrm{P}} \mathrm{Q}_{\mathrm{P}}}{36 \eta_{\mathrm{P}}}$ 
Where $E_{p}$ is the energy consumption $(\mathrm{kW}), \mathrm{Q}_{\mathrm{P}}$ is the flow rate $\left(\mathrm{m}^{3} \mathrm{~h}^{-1}\right) \Delta \mathrm{P}_{\mathrm{p}}$ is the differential head of the pump (bar), and $\eta_{\mathrm{p}}$ is the pump efficiency (85\%).

The blower energy requirements for gas sparging were calculated using Eq. 7 (Pretel et al., 2014).

$P_{B}=\frac{M \cdot R \cdot T}{(\alpha-1) \cdot \eta_{B}} \cdot\left[\left(\frac{P_{2}}{P_{1}}\right)^{\frac{\alpha-1}{\alpha}}-1\right]$

Where $\mathrm{P}_{\mathrm{B}}$ is the blower consumption $(\mathrm{W}), \mathrm{M}$ is the molar flow rate of biogas ( $\mathrm{mol} \mathrm{s}^{-1}$ ), $\mathrm{R}$ is the gas constant $\left(\mathrm{J} \mathrm{mol}^{-1} \mathrm{~K}^{-1}\right), \mathrm{T}$ is the biogas temperature $\left({ }^{\circ} \mathrm{K}\right), \alpha$ is the adiabatic coefficient, $\eta_{\mathrm{B}}$ is the blower efficiency $(80 \%), \mathrm{P}_{2}$ is the absolute impulsion pressure of the blower (atm), and $\mathrm{P}_{1}$ is the absolute inlet pressure of the blower (atm).

The energy cost to dehydrate the AnMBR sludge by centrifugation was $0.045 \mathrm{kWh} \mathrm{kg}^{-1} \mathrm{TSS}$ (Pretel et al., 2014). Electrolyte dosing was set at $6 \mathrm{~kg} \mathrm{t}^{-1}$ TSS (Pretel et al., 2014b). No sludge disposal cost nor benefit was included. However, it was considered that the sludge would be highly stable (due to the 60 day SRT), and hence suitable to be reused as fertiliser (Pretel et al., 2015, 2014).

The membrane cleaning protocol included (i) a clean in place (CIP) performed once a week with $500 \mathrm{mg} \mathrm{L}^{-1}$ and $2000 \mathrm{mg} \mathrm{L}^{-1}$ of sodium hypochlorite and citric acid, respectively, and (ii) two annual cleaning out of place (COP) with $1000 \mathrm{mg} \mathrm{L}^{-1}$ and 2000 $\mathrm{mg} \mathrm{L}^{-1}$ sodium hypochlorite and citric acid, respectively (Brepols et al., 2008; Verrecht et al., 2010).

\subsection{FO-RO+AnMBR plant economic evaluation}

The CAPEX and OPEX were calculated for the different scenarios. Benefits coming from biogas and water production were not considered in this study, since these benefits are rarely accounted for in the water sector (Maurer, 2009). Therefore, the discounted lifetime 
costs (DLC) of each option were calculated as the sum of the CAPEX and discounted OPEX during the plant lifetime (Eq. 8) (Maurer, 2009; Roefs et al., 2016). The levelised cost method was used to obtain the unit cost of water production and wastewater treatment. This method is based on the price at which the outputs would have to be sold to incur a positive net present value. The unit cost was calculated by dividing the DLC by the discounted output produced throughout the lifetime (Eq. 9 and 10) (Papapetrou et al., 2017).

$\operatorname{DLC}(€)=\operatorname{CAPEX}+\sum_{\mathrm{t}=1}^{\mathrm{T}} \frac{\mathrm{OPEX}_{\mathrm{t}}}{(1+\mathrm{i})^{\mathrm{t}}}$

Water production cost $\left(€ \cdot \mathrm{m}^{-3}\right)=\frac{\mathrm{DLC}}{\sum_{\mathrm{t}=1}^{\mathrm{T}} \frac{\mathrm{M}_{\mathrm{Wt}}}{(1+\mathrm{i})^{\mathrm{t}}}}$

Wastewater treatment cost $\left(€ \cdot \mathrm{m}^{-3}\right)=\frac{\mathrm{DLC}}{\sum_{\mathrm{t}=1}^{\mathrm{T}} \frac{\mathrm{M}_{\mathrm{WWt}}}{(1+\mathrm{i})^{\mathrm{t}}}}$

Where $\mathrm{OPEX}_{\mathrm{t}}$ is the OPEX at time $\mathrm{t}(€), \mathrm{i}$ is the discount rate $(5 \%), \mathrm{t}$ is the plant lifetime (20 years), $M w_{t}$ represents the volume of water produced at year $\mathrm{t}\left(\mathrm{m}^{3}\right)$, and $\mathrm{Mww}_{\mathrm{t}}$ represents the volume of wastewater treated at year $\mathrm{t}\left(\mathrm{m}^{3}\right)$.

\section{Results and discussion}

\subsection{FO-RO costs for reclaimed water production}

Figure 2a shows the unit cost of the water produced by FO-RO system for each scheme and scenario. The economy of FO-RO process is driven by (i) the low water flux performance and the larger number of FO membranes needed to achieve higher FO recoveries (i.e. $50 \%$ recovery in Scenario 1, $80 \%$ recovery in Scenario 2, and $90 \%$ recovery in Scenario 3) and by (ii) the osmotic pressure difference decrease between both sides of the membrane as the FO recovery increases. The latter phenomenon is particularly relevant since it makes the membrane area exponentially increases with FO recovery (Cath et al., 2010). This hinders the economic feasibility of the scenarios with an FO recovery of 80 and $90 \%$. 
Regarding the different schemes, Scheme A features the lowest water production cost per $\mathrm{m}^{3}$ of water produced. The lower unit cost of Scheme A is a result of the much higher water production when compared to Scheme B and Scheme C (Table 1), which minimises the impact of the FO capital and operating costs. The closed-loop configuration (Scheme C) presents the worst economic prospect for water production, mainly due to the cost related to the replenishment of the synthetic draw solution. In Scheme C, the RO stage is used to re-concentrate the diluted draw solution. Consequently, the diffusion of $\mathrm{NaCl}$ through $\mathrm{FO}$ and $\mathrm{RO}$ membranes requires the addition of $\mathrm{NaCl}$ to keep the draw solution osmotic pressure constant that leads to higher OPEX.

Figure $2 b$ shows the cost distribution of the closed-loop scheme for the three different FO recovery scenarios. CAPEX represents between 41 and $45 \%$ of the total cost. Concerning the OPEX, energy consumption and the replacement of the FO membranes are the major OPEX contributors. The contribution of the energy consumption in Scheme C (14-19\%) is lower than the values reported for conventional seawater reverse osmosis (SWRO) plants which averages 30-40\% (Blandin et al., 2015; Valladares Linares et al., 2016). This difference is attributed to (i) the lower energy consumption of FO-RO system compared to conventional SWRO due to the lower osmotic pressure of the diluted draw solution; and (ii) the significant contribution of the FO stage to the total cost. Figure $2 b$ shows that higher FO recoveries lower energy costs. However, increasing the FO recovery is accompanied by a significant increase in the costs associated with FO membrane replacement. In the case of 90\% FO recovery (Scenario 3C), FO membrane replacement (21\%) cost outweighs the cost of energy (14\%). These results highlight the importance of improving FO performance and durability on the economic feasibility of the FO-RO system. 
The lowest water production cost obtained from the different alternatives is $0.80 € \mathrm{~m}^{-3}$ (Scenario 1A), which is an $18 \%$ higher than the average cost of $0.76 \$ \mathrm{~m}^{-3}$ reported for SWRO plants (Blandin et al., 2015). The CAPEX of an FO-RO system will always be higher than that of an SWRO system due to the costs associated with the FO stage. Therefore, the economic reliability of the FO-RO system is linked to potential energy savings which have been reported to reduce OPEX (Cath et al., 2010; Valladares Linares et al., 2016; Wan and Chung, 2018). In this study, energy savings are reached for all FORO systems when compared to typical SWRO values, however, these savings do not account for more than $17 \%$ of the total energy consumption (see Section 3.4). This value is in agreement with other conservative energy savings reported in the literature (Awad et al., 2019; Choi et al., 2017). The installation of advanced energy recovery devices (e.g. pressure exchangers) in SWRO plants has significantly improved its energy efficiency, thus narrowing the room for improvement of the FO-RO technology. The present study shows that there is a compromise among energy savings, CAPEX and other OPEX such as membrane replacement, labour, maintenance or draw solution replenishment. Therefore, it can be concluded that the economic competitiveness of the FO-RO technology goes beyond energy savings.

\subsection{AnMBR costs for sewage treatment and biogas production}

Figure 3a shows the wastewater treatment cost related to the AnMBR stage for the different scenarios under study. The incorporation of the FO stage leads to a noticeable reduction of the AnMBR costs. This cost reduction is related to the lower influent flow and the associated lower digester volume, lower membrane area, and lower energy requirements for gas sparging, among others. Additionally, although it has not been included in this techno-economic analysis, it might also reduce the AnMBR footprint. 
CAPEX is the most important contributor to the AnMBR total cost representing between 63 and $77 \%$ of it, being the digester construction and membrane acquisition the major capital costs. In this study, an HRT of 1 day was selected, although lower HRTs $(<10 \mathrm{~h})$ would further decrease CAPEX costs (Stuckey, 2012). However, the technical feasibility of extremely short HRTs is questionable when combined with FO pre-concentration, due to the increased MLSS concentration in the bioreactor and the resulting increase of both the SGD and the recirculation flow from the bioreactor to the membrane tank. Moreover, short HRTs may reduce the COD removal efficiency (Maaz et al., 2019). Therefore, FO+AnMBR systems operated at HRTs below 1 day are not expected to provide economic benefits, particularly when treating highly concentrated influents such as in Scenario 2 (80\% FO recovery) and Scenario 3 (90\% FO recovery).

OPEX contribution to the AnMBR total cost is relatively low, even more when compared to the conventional activated sludge system, due to the low energy requirements (no aeration requirements) and the low sludge handling cost (less sludge production). The energy consumption of the fouling control method (i.e. gas sparging) and, to a lesser extent, the recirculation pump, are the main OPEX contributors of the AnMBR. Thereby, energy cost optimisation should target these two parameters.

The SRT is an important operational parameter to optimise OPEX of MBR systems (Verrecht et al., 2010). MLSS concentration decreases at lower SRTs and, accordingly, both SGDs and recirculation flow decrease. Furthermore, a lower MLSS concentration is expected to alleviate membrane fouling, which might have a direct influence on the membrane lifespan (i.e. membrane replacement costs) and chemical cleaning requirements (Ozgun et al., 2013). Decreasing SRT and increasing the sludge production would have a minimum impact on the AnMBR OPEX since sludge handling contributes 
less than 5\% to the OPEX. However, in cold climates, decreasing SRT could jeopardize the efficiency of the biological process due to the slower kinetics of the anaerobic microbes at psychrophilic temperatures (Maaz et al., 2019). Regardless of the operational temperature, the influence of SRT on AnMBR performance is expected to progressively increase with the increase of the FO recovery as a result of the higher organic loading rates. Therefore, the SRT should be optimised for each FO recovery with the aim of improving the AnMBR performance while keeping reasonable operating costs. Membrane replacement is the other main contributor to the AnMBR OPEX due to the large membrane area required to achieve the permeate flux and the relatively short lifespan of membrane modules (5-10 years). Low membrane flux is recognised as one of the main economic bottlenecks slowing the progress of the AnMBR technology (Lin et al., 2011; Ozgun et al., 2013).

Increasing membrane fluxes would have a positive effect on the CAPEX costs, however, it can be accompanied by an increase in OPEX owing to the higher SGDs required. Verrecht et al. (2010) noticed that increasing the flux of aerobic MBRs from 15 to 30 LMH reduced the net present value (NPV) by $9 \%$ despite the higher OPEX. However, special attention should be given when combining FO pre-concentration with high membrane fluxes (>15 LMH) since the higher MLSS concentrations can exponentially increase the SGDs to keep a stable flux. This could compromise the economic feasibility of AnMBR plants.

\subsection{FO-RO+AnMBR cost for integrated sewage treatment and water production}

Figure $3 b$ shows the unit cost of wastewater treatment per $\mathrm{m}^{3}$ of wastewater treated for the entire FO-RO+AnMBR system. The economics of the system is governed by FO-RO system since it accounts for more than $74 \%$ of the total cost in all scenarios. The 
contribution of the FO-RO system increases as the FO recovery increases. For instance, in Scheme A, the contribution of the FO-RO system to the total cost increases from $75 \%$ in Scenario 1 (50\% FO recovery) to $90 \%$ and 94\% for Scenario 2 (80\% FO recovery) and Scenario 3 (90\% FO recovery), respectively. As discussed in Section 3.2, the higher the FO recovery, the lower the AnMBR cost (Figure 3a). However, the reduced AnMBR cost does not offset the cost of the FO-RO system. Accordingly, the 50\% FO recovery scenarios present the lowest wastewater treatment cost when compared to the $80 \%$ and 90\% FO recovery scenarios (Figure 3b).

Scenario 1C (i.e. 50\% FO recovery in a closed-loop scheme) is the most economical scenario $\left(0.81 € \mathrm{~m}^{-3}\right)$ owing to the lower water production in the RO step (i.e. $33 \%$ recovery), which reduces both CAPEX and OPEX. However, the inclusion of benefits coming from water production could change the economic prospect of this scenario since it presents the lowest water production (Table 1). In Scenarios 2 and 3, with higher FO and $\mathrm{RO}$ recoveries and higher water productions, Scheme B is cheaper than Scheme C since draw solution replenishment is not needed. $\mathrm{NaCl}$ is the most widespread draw solution, however, other solutes (e.g. $\mathrm{Mg}^{+2}$, organic) could be considered to reduce retrodiffusion flux (Lee and Hsieh, 2019). Alternative solutes would increase the initial chemicals acquisition investment. Nevertheless, these would be negligible compared to the OPEX savings resulting from the reduced draw solution replenishment cost and the higher osmotic pressure of the solution. An ideal solute should have a low retro-diffusion flux and little impact on microbial activity and digestate quality.

Scheme A, where the production of water is maximised, is the most expensive alternative for wastewater treatment, due to the high cost of the RO installations. Accordingly, this scheme is suitable in coastal regions lacking fresh water, where these higher costs are 
offset by the benefits obtained from water production. Otherwise, restricting the RO recovery to $45 \%$ (Scheme B) is the most favourable condition for areas without water scarcity (Blandin et al., 2015; Teusner et al., 2017).

The estimated cost from plants combining wastewater treatment and fresh water production (e.g., $\mathrm{MBR}+\mathrm{RO}, \mathrm{MBR}+\mathrm{RO}+\mathrm{AOP}$ and $\mathrm{CAS}+\mathrm{UF}+\mathrm{RO}$ ) ranges from 0.6 to 1.0 $€$ per $\mathrm{m}^{3}$ of wastewater treated (Valladares Linares et al., 2016; Verstraete et al., 2009). Scenario 1 ( $50 \%$ of FO recovery) is the only competitive economic alternative for combined wastewater treatment and water production since the treatment cost ranges between 0.81 and $0.97 €$ per $\mathrm{m}^{3}$ of wastewater treated (Figure 3b). These results corroborate that improving FO membranes fluxes is paramount to make this technology competitive.

The competitiveness of the FO-RO+AnMBR system is worsened when compared with stand-alone AnMBR (baseline scenario) since the wastewater treatment cost of the standalone AnMBR is half than the cheapest FO-RO scenario (Scenario 1C). Nevertheless, including incomes from biogas and water production as well as other factors such as the dual barrier for pollutants provided by FO-RO system (e.g. improving social perception of water produced, increasing pollutants rejection) might improve the overall competitiveness of FO-RO+AnMBR system.

\subsection{Economic prospect of retrofitting an SWRO into an FO-RO+AnMBR plant}

The FO-RO+AnMBR system is not yet economically feasible when compared to an SWRO plant or stand-alone AnMBR. However, as technology develops, some schemes combining water production and wastewater treatment could make FO-RO+AnMBR a suitable alternative. Indeed, the incorporation of FO stage to an existing SWRO plant has been identified as an attractive scenario for FO technology (Blandin et al., 2016; Teusner 
et al., 2017). This approach may be an attractive alternative in coastal areas undergoing rapid urbanisation, where the increased population overloads the existing WWTP infrastructure and increases the demand of fresh water (Li et al., 2014). Such coastal areas may require at some point to increase the capacity of the WWTP or construct a new WWTP and, in places where there is a nearby SWRO plant, retrofitting the conventional SWRO to an FO-RO system could be a competitive alternative. Although implementing an FO stage would incur extra capital and operating expenses, these might be compensated by the lower wastewater treatment cost when combining seawater desalination and wastewater treatment plants.

The scheme under study incorporated an FO stage into an SWRO plant since this scenario is considered to be the best approach to reduce an SWRO plant energy consumption (Blandin et al., 2016). The FO recovery (i.e. 50, 80 or 90\%) affects both (i) the wastewater concentration and flow rate of the AnMBR influent and (ii) the seawater osmotic pressure and flow rate feeding the RO stage. The concentrated wastewater was fed into a newly constructed AnMBR. The three FO recovery scenarios were compared to the baseline SWRO plant to assess the energy savings related to seawater dilution. All the scenarios were evaluated on the basis of a final water production of 45,000 $\mathrm{m}^{3} \mathrm{day}^{-1}$ (Blandin et al., 2015).

Figure 4 shows that adding an FO stage in an existing SWRO plant combined with AnMBR treatment is economically competitive for a 50\% FO recovery. Figure 4 also shows that as the FO recovery increases and the FO cost increases, the cost savings from AnMBR also increases (primarily due to the lower digester volume and the lower membrane surface). However, when the FO recovery is $80 \%$, the lower AnMBR cost does not offset the costs associated with the FO stage. 
To incorporate the FO process into a SWRO plant leads to improving the energy efficiency of the desalination plant (energy saving $=11.5,15.0$ and $16.2 \%$ for FO recoveries of 50, 80 and 90\%, respectively). However, this situation does not always relate to a better economic prospect. As a matter of fact, the low fluxes of the FO membranes have a major impact on the process economics than energy consumption. A clear example is Scenario 3 (i.e. $90 \%$ FO recovery) which displays the worse economic prospect with a benefit-cost ratio (BCR) of 0.65 despite being the scenario that has the highest energy saving. Accordingly, considering the current development of FO technology, FO recoveries around 50\% appear as the most suitable condition to integrate FO-RO+AnMBR technology.

\subsection{Sensitivity analysis of the flux impact on FO-RO+AnMBR economics}

The low water fluxes reported for FO membranes is the main bottleneck of FO technology. Therefore, improving membrane fluxes is crucial to boost the competitiveness of FO technology. In this regard, the sensitivity analysis shows that the wastewater treatment costs sharply decrease as the FO water fluxes increase from $1 \mathrm{LMH}$ to $10 \mathrm{LMH}$ (Figure 5). The impact of water fluxes is particularly relevant for Scenario 2 and 3 (i.e. 80 and $90 \%$ of recovery) where higher water permeation through the FO membranes are required. Water fluxes above $10 \mathrm{LMH}$ only lead to small improvements in the wastewater treatment costs. This is due to the fact that as the FO fluxes increase the influence of the FO stage (e.g. membrane replacement, labour, maintenance) on the process total cost is minimised.

Scenario 1 is the most competitive, although the differences with Scenario 2 and 3 are substantially narrowed when FO fluxes increase (>10 LMH). In fact, when the water flux 
is above $20 \mathrm{LMH}$, the Scenario 2B outcompetes Scenario $1 \mathrm{~B}$ emphasising the windows of opportunities that high FO recoveries would open.

When the FO flux is higher than $10 \mathrm{LMH}$, closed-loop schemes with FO recoveries below or equal to $80 \%$ (Scenario 1 and 2) are more economically competitive than open-loop schemes, due to (i) the reduction in membrane area is accompanied by a reduction in the retro-diffusion flow rate and (ii) the intake/outfall and pre-treatment of seawater becomes costlier than that required for draw solution replenishment. However, it is important to consider that the accumulation of contaminants in the draw solution may occur in closedloop systems, which may reduce the quality of the recovered water in these schemes (Blandin et al., 2016; D’Haese et al., 2013).

From the sensitivity analysis, it can be concluded that increasing FO flux up to $10 \mathrm{LMH}$ can reduce the wastewater costs to values below $0.8 € \mathrm{~m}^{-3}$, being Scenario $1 \mathrm{C}$ the most cost-effective one with a treatment cost of $0.70 € \mathrm{~m}^{-3}$ (Figure 5). This cost would be further reduced if incomes coming from biogas production and, especially, water production were considered. Finally, it is worth to mention that membrane fluxes for FO pilot plants range from 2.2 to 10.6 LMH (Awad et al., 2019). Thus, it is conceivable that fluxes around $10 \mathrm{LMH}$ could be achieved soon for scenarios with water recoveries around 50\%. However, in scenarios with higher water recoveries (e.g. 80 and 90\%) reaching a flux of $10 \mathrm{LMH}$ still requires further technology advances since it would be required to double or triple current fluxes.

\section{Conclusions}

The feasibility of combining FO, RO and AnMBR technologies for wastewater treatment with energy and water production was investigated. The minimum wastewater treatment cost was $0.81 € \mathrm{~m}^{-3}$ when FO recovery was restricted to $50 \%$ in a closed-loop scheme. 
The treatment cost increased to 1.01 and $1.27 € \mathrm{~m}^{-3}$ for FO recoveries of $80 \%$ and $90 \%$, respectively. The minimum fresh water production cost was estimated at 0.80 and $1.16 €$ $\mathrm{m}^{-3}$ for an open-loop and a closed-loop scheme. The sensitivity analysis showed that reaching FO fluxes of $10 \mathrm{LMH}$ would significantly improve the competitiveness of FORO+AnMBR system for sewage treatment.

\section{Supplementary information}

E-supplementary data of this work can be found in online version of the paper.

\section{Acknowledgments}

The authors acknowledge the LIFE Green Sewer project (LIFE17 ENV/ES/000341) for the financial support. Sergi Vinardell is grateful to the Generalitat de Catalunya for his predoctoral FI grant (2019FI_B 00394). Sergi Astals is grateful to the Spanish Ministry of Science, Innovation and Universities for his Ramon y Cajal fellowship (RYC-201722372). The authors thank Miriam Peces from Aalborg University (Denmark) for her scientific contribution and proofreading the manuscript.

\section{References}

1. Ansari, A.J., Hai, F.I., Price, W.E., Drewes, J.E., Nghiem, L.D., 2017. Forward osmosis as a platform for resource recovery from municipal wastewater - A critical assessment of the literature. J. Memb. Sci. 529, 195-206.

2. Ansari, A.J., Hai, F.I., Price, W.E., Ngo, H.H., Guo, W., Nghiem, L.D., 2018. Assessing the integration of forward osmosis and anaerobic digestion for simultaneous wastewater treatment and resource recovery. Bioresour. Technol. 260, 221-226.

3. Awad, A.M., Jalab, R., Minier-Matar, J., Adham, S., Nasser, M.S., Judd, S.J., 2019. The status of forward osmosis technology implementation. Desalination 461, 10-21.

4. Blandin, G., Verliefde, A.R.D., Comas, J., Rodriguez-Roda, I., Le-Clech, P., 2016. 
Efficiently combining water reuse and desalination through forward osmosis-reverse osmosis (FO-RO) hybrids: A critical review. Membranes (Basel). 6, 37.

5. Blandin, G., Verliefde, A.R.D., Tang, C.Y., Le-Clech, P., 2015. Opportunities to reach economic sustainability in forward osmosis-reverse osmosis hybrids for seawater desalination. Desalination 363, 26-36.

6. Brepols, C., Drensla, K., Janot, A., Trimborn, M., Engelhardt, N., 2008. Strategies for chemical cleaning in large scale membrane bioreactors. Water Sci. Technol. 57, 457-463.

7. Cashman, S., Ma, X., Mosley, J., Garland, J., Crone, B., Xue, X., 2018. Energy and greenhouse gas life cycle assessment and cost analysis of aerobic and anaerobic membrane bioreactor systems: Influence of scale, population density, climate, and methane recovery. Bioresour. Technol. 254, 56-66.

8. Cath, T.Y., Childress, A.E., Elimelech, M., 2006. Forward osmosis: Principles, applications, and recent developments. J. Memb. Sci. 281, 70-87.

9. Cath, T.Y., Hancock, N.T., Lundin, C.D., Hoppe-Jones, C., Drewes, J.E., 2010. A multibarrier osmotic dilution process for simultaneous desalination and purification of impaired water. J. Memb. Sci. 362, 417-426.

10. Choi, B.G., Zhan, M., Shin, K., Lee, S., Hong, S., 2017. Pilot-scale evaluation of FO-RO osmotic dilution process for treating wastewater from coal-fired power plant integrated with seawater desalination. J. Memb. Sci. 540, 78-87.

11. D’Haese, A., Le-Clech, P., Van Nevel, S., Verbeken, K., Cornelissen, E.R., Khan, S.J., Verliefde, A.R.D., 2013. Trace organic solutes in closed-loop forward osmosis applications: Influence of membrane fouling and modeling of solute build-up. Water Res. $47,5232-5244$.

12. Deshmukh, A., Yip, N.Y., Lin, S., Elimelech, M., 2015. Desalination by forward osmosis: 
Identifying performance limiting parameters through module-scale modeling. J. Memb. Sci. 491, 159-167.

13. Ferrari, F., Balcazar, J.L., Rodriguez-Roda, I., Pijuan, M., 2019. Anaerobic membrane bioreactor for biogas production from concentrated sewage produced during sewer mining. Sci. Total Environ. 670, 993-1000.

14. Ferrer, J., Pretel, R., Durán, F., Giménez, J.B., Robles, A., Ruano, M. V., Serralta, J., Ribes, J., Seco, A., 2015. Design methodology for submerged anaerobic membrane bioreactors (AnMBR): A case study. Sep. Purif. Technol. 141, 378-386.

15. Garrido-Baserba, M., Vinardell, S., Molinos-Senante, M., Rosso, D., Poch, M., 2018. The Economics of Wastewater Treatment Decentralization: A Techno-economic Evaluation. Environ. Sci. Technol. 52, 8965-8976.

16. Giménez, J.B., Robles, A., Carretero, L., Durán, F., Ruano, M. V., Gatti, M.N., Ribes, J., Ferrer, J., Seco, A., 2011. Experimental study of the anaerobic urban wastewater treatment in a submerged hollow-fibre membrane bioreactor at pilot scale. Bioresour. Technol. 102, 8799-8806.

17. Guest, J.S., Skerlos, S.J., Barnard, J.L., Beck, M.B., Daigger, G.T., Hilger, H., Jackson, S.J., Karvazy, K., Kelly, L., Macpherson, L., Mihelcic, J.R., Pramanik, A., Raskin, L., Van Loosdrecht, M.C.M., Yeh, D., Love, N.G., 2009. A new planning and design paradigm to achieve sustainable resource recovery from wastewater. Environ. Sci. Technol. 43, 6126-6130.

18. Hancock, N.T., Black, N.D., Cath, T.Y., 2012. A comparative life cycle assessment of hybrid osmotic dilution desalination and established seawater desalination and wastewater reclamation processes. Water Res. 46, 1145-1154.

19. Hu, A.Y., Stuckey, D.C., 2007. Activated Carbon Addition to a Submerged Anaerobic 
Membrane Bioreactor: Effect on Performance, Transmembrane Pressure, and Flux. J. Environ. Eng. 133, 73-80.

20. Itliong, J.N., Villagracia, A.R.C., Moreno, J.L. V., Rojas, K.I.M., Bernardo, G.P.O., David, M.Y., Manrique, R.B., Ubando, A.T., Culaba, A.B., Padama, A.A.B., Ong, H.L., Chang, J.S., Chen, W.H., Kasai, H., Arboleda, N.B., 2019. Investigation of reverse ionic diffusion in forward-osmosis-aided dewatering of microalgae: A molecular dynamics study. Bioresour. Technol. 279, 181-188.

21. Jalab, R., Awad, A.M., Nasser, M.S., Minier-Matar, J., Adham, S., Judd, S.J., 2019. An empirical determination of the whole-life cost of FO-based open-loop wastewater reclamation technologies. Water Res. 163, 114879.

22. Judd, S.J., 2017. Membrane technology costs and me. Water Res. 122, 1-9.

23. Kim, J.E., Phuntsho, S., Chekli, L., Hong, S., Ghaffour, N., Leiknes, T.O., Choi, J.Y., Shon, H.K., 2017. Environmental and economic impacts of fertilizer drawn forward osmosis and nanofiltration hybrid system. Desalination. 416, 76-85.

24. Lee, D.J., Hsieh, M.H., 2019. Forward osmosis membrane processes for wastewater bioremediation: Research needs. Bioresour. Technol. 290, 121795.

25. Li, Z., Valladares Linares, R., Abu-Ghdaib, M., Zhan, T., Yangali-Quintanilla, V., Amy, G., 2014. Osmotically driven membrane process for the management of urban runoff in coastal regions. Water Res. 48, 200-209.

26. Lin, H., Chen, J., Wang, F., Ding, L., Hong, H., 2011. Feasibility evaluation of submerged anaerobic membrane bioreactor for municipal secondary wastewater treatment. Desalination. 280, 120-126.

27. Luo, H., Wang, Q., Zhang, T.C., Tao, T., Zhou, A., Chen, L., Bie, X., 2014. A review on the recovery methods of draw solutes in forward osmosis. J. Water Process Eng. 4, $212-$ 
223.

28. Maaz, M., Yasin, M., Aslam, M., Kumar, G., Atabani, A.E., Idrees, M., Anjum, F., Jamil, F., Ahmad, R., Khan, A.L., Lesage, G., Heran, M., Kim, J., 2019. Anaerobic membrane bioreactors for wastewater treatment: Novel configurations, fouling control and energy considerations. Bioresour. Technol. 283, 358-372.

29. Martinez-Sosa, D., Helmreich, B., Netter, T., Paris, S., Bischof, F., Horn, H., 2011. Anaerobic submerged membrane bioreactor (AnSMBR) for municipal wastewater treatment under mesophilic and psychrophilic temperature conditions. Bioresour. Technol. 102, 10377-10385.

30. Maurer, M., 2009. Specific net present value: An improved method for assessing modularisation costs in water services with growing demand. Water Res. 43, 2121-2130.

31. McCarty, P.L., Bae, J., Kim, J., 2011. Domestic wastewater treatment as a net energy producer - can this be achieved? Environ. Sci. Technol. 45, 7100-7106.

32. Ozgun, H., Dereli, R.K., Ersahin, M.E., Kinaci, C., Spanjers, H., Van Lier, J.B., 2013. A review of anaerobic membrane bioreactors for municipal wastewater treatment: Integration options, limitations and expectations. Sep. Purif. Technol. 118, 89-104.

33. Papapetrou, M., Cipollina, A., Commare, U. La, Micale, G., Zaragoza, G., Kosmadakis, G., 2017. Assessment of methodologies and data used to calculate desalination costs. Desalination 419, 8-19.

34. Pretel, R., Robles, A., Ruano, M. V., Seco, A., Ferrer, J., 2014. The operating cost of an anaerobic membrane bioreactor (AnMBR) treating sulphate-rich urban wastewater. Sep. Purif. Technol. 126, 30-38.

35. Pretel, R., Shoener, B.D., Ferrer, J., Guest, J.S., 2015. Navigating environmental, economic, and technological trade-offs in the design and operation of submerged 
anaerobic membrane bioreactors (AnMBRs). Water Res. 87, 531-541.

36. Prieto, A.L., Futselaar, H., Lens, P.N.L., Bair, R., Yeh, D.H., 2013. Development and start up of a gas-lift anaerobic membrane bioreactor (Gl-AnMBR) for conversion of sewage to energy, water and nutrients. J. Memb. Sci. 441, 158-167.

37. Puyol, D., Batstone, D.J., Hülsen, T., Astals, S., Peces, M., Krömer, J.O., 2017. Resource recovery from wastewater by biological technologies: Opportunities, challenges, and prospects. Front. Microbiol. 7.

38. Robles, A., Ruano, M. V., Ribes, J., Ferrer, J., 2013. Factors that affect the permeability of commercial hollow-fibre membranes in a submerged anaerobic MBR (HF-SAnMBR) system. Water Res. 47, 1277-1288.

39. Roefs, I., Meulman, B., Vreeburg, J.H.G., Spiller, M., 2016. Centralised , decentralised or hybrid sanitation systems? Economic evaluation under urban development uncertainty and phased expansion. Water Res. 109, 274-286.

40. Ruigómez, I., Vera, L., González, E., Rodríguez-Sevilla, J., 2016. Pilot plant study of a new rotating hollow fibre membrane module for improved performance of an anaerobic submerged MBR. J. Memb. Sci. 514, 105-113.

41. Shaffer, D.L., Werber, J.R., Jaramillo, H., Lin, S., Elimelech, M., 2015. Forward osmosis: Where are we now? Desalination. 356, 271-284.

42. Shin, C., Bae, J., 2018. Current status of the pilot-scale anaerobic membrane bioreactor treatments of domestic wastewaters: A critical review. Bioresour. Technol. 247, 10381046.

43. Smith, A.L., Stadler, L.B., Cao, L., Love, N.G., Raskin, L., Skerlos, S.J., 2014. Navigating Wastewater Energy Recovery Strategies: A Life Cycle Comparison of Anaerobic Membrane Bioreactor and Conventional Treatment Systems with Anaerobic 
Digestion. Environ. Sci. Technol. 48, 5972-5981.

44. Stuckey, D.C., 2012. Recent developments in anaerobic membrane reactors. Bioresour. Technol. 122, 137-148.

45. Teusner, A., Blandin, G., Le-Clech, P., 2017. Augmenting water supply by combined desalination/water recycling methods: an economic assessment. Environ. Technol. (United Kingdom) 38, 257-265.

46. Tiraferri, A., Yip, N.Y., Straub, A.P., Romero-Vargas Castrillon, S., Elimelech, M., 2013. A method for the simultaneous determination of transport and structural parameters of forward osmosis membranes. J. Memb. Sci. 444, 523-538.

47. Valladares Linares, R., Li, Z., Yangali-Quintanilla, V., Ghaffour, N., Amy, G., Leiknes, T., Vrouwenvelder, J.S., 2016. Life cycle cost of a hybrid forward osmosis - low pressure reverse osmosis system for seawater desalination and wastewater recovery. Water Res. $88,225-234$.

48. Verrecht, B., Maere, T., Nopens, I., Brepols, C., Judd, S., 2010. The cost of a large-scale hollow fibre MBR. Water Res. 44, 5274-5283.

49. Verstraete, W., Van de Caveye, P., Diamantis, V., 2009. Maximum use of resources present in domestic “used water.” Bioresour. Technol. 100, 5537-5545.

50. Wan, C.F., Chung, T.S., 2018. Techno-economic evaluation of various RO+PRO and RO+FO integrated processes. Appl. Energy 212, 1038-1050. 
Table 1. Description and water production for the different FO-RO+AnMBR scenarios.

\begin{tabular}{cccc}
\hline Scheme goals & Scenario 1 & Scenario 2 & Scenario 3 \\
& $($ FOrecovery 50\%) & $($ FOrecovery 80\%) & $($ FOrecovery 90\%)
\end{tabular}

\begin{tabular}{|c|c|c|c|c|}
\hline $\begin{array}{l}\text { Scheme A } \\
\left(\mathrm{m}^{3} \mathrm{~d}^{-1}\right)\end{array}$ & $\begin{array}{c}\text { Open-loop maximising } \\
\text { water production }\left(\pi_{\mathrm{brine}}=\right. \\
46.7 \mathrm{bar})\end{array}$ & 4218 & 5550 & 5994 \\
\hline $\begin{array}{l}\text { Scheme B } \\
\qquad\left(\mathrm{m}^{3} \mathrm{~d}^{-1}\right)\end{array}$ & $\begin{array}{c}\text { Open-loop with limited } \\
\text { water production ( } 45 \% \text { RO } \\
\text { recovery) }\end{array}$ & 2997 & 3596 & 3796 \\
\hline $\begin{array}{l}\text { Scheme C } \\
\qquad\left(\mathrm{m}^{3} \mathrm{~d}^{-1}\right)\end{array}$ & $\begin{array}{l}\text { Closed-loop using a } \\
\text { synthetic draw solution of } \\
\mathrm{NaCl}\left(\pi_{\text {initial }}=25.7 \text { bar }\right)\end{array}$ & 2220 & 3552 & 3996 \\
\hline
\end{tabular}


(a)

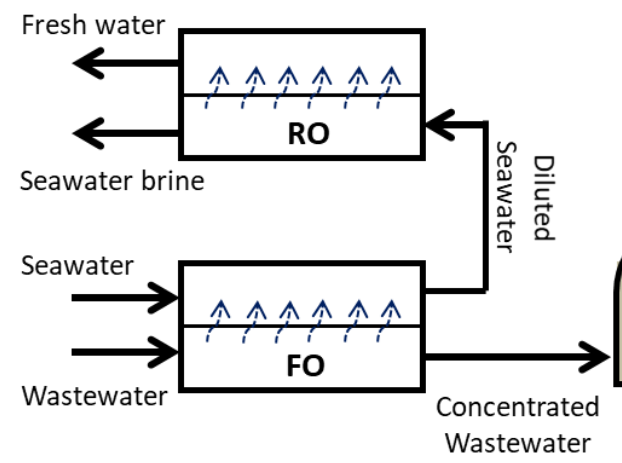

(b)

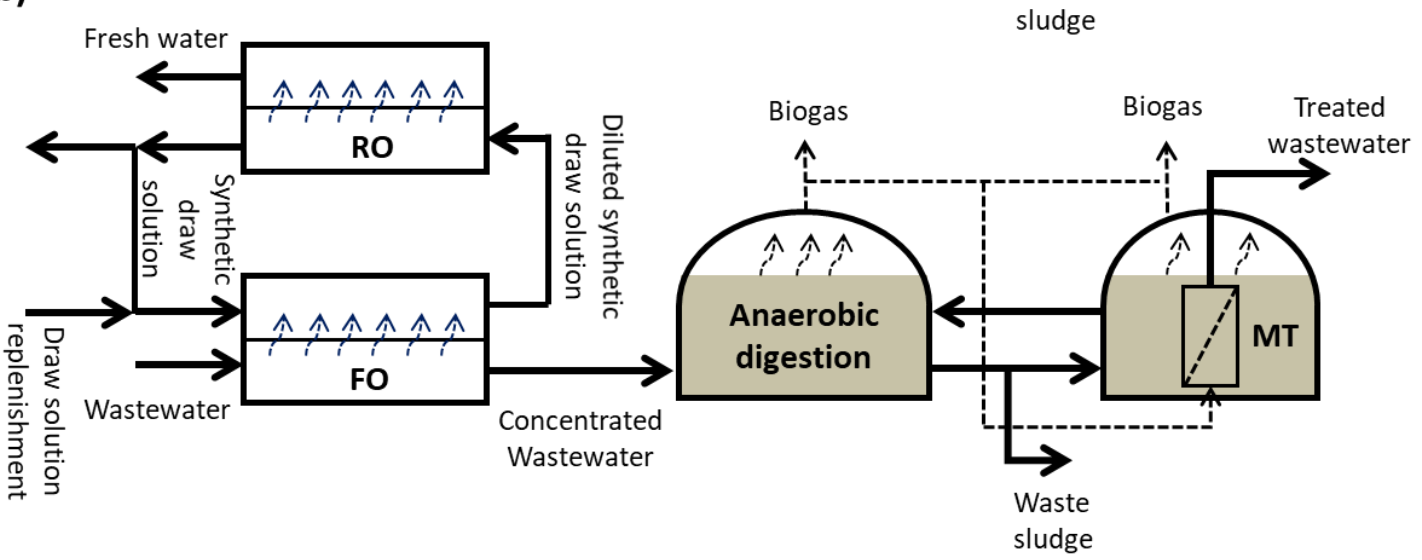

Figure 1. Schematic representation of FO-RO+AnMBR.process. (a) Open-loop scheme; (b) Closed-loop scheme. (MT: Membrane Tank; FO: Forward Osmosis; RO: Reverse Osmosis). 
(a)

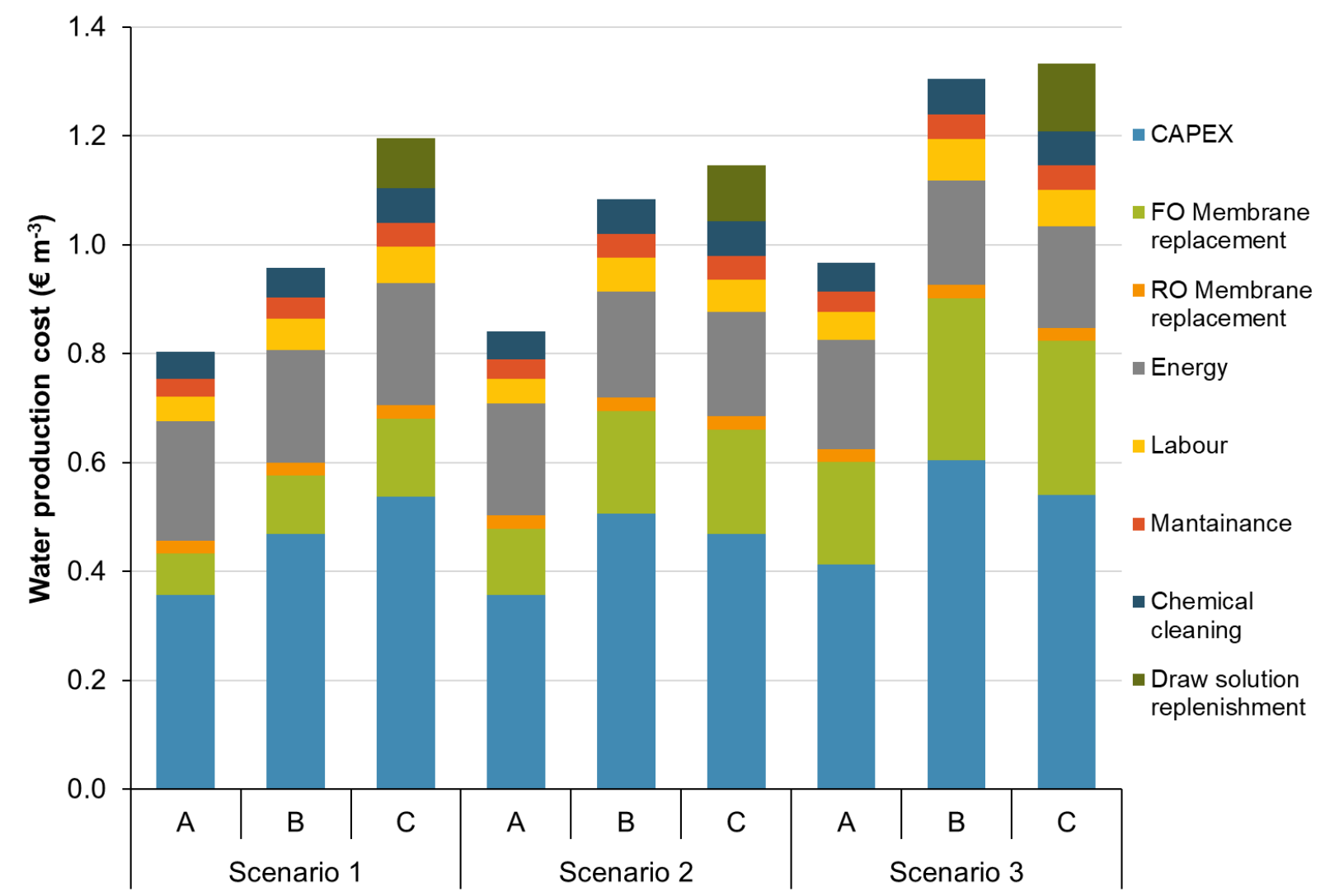

(b)

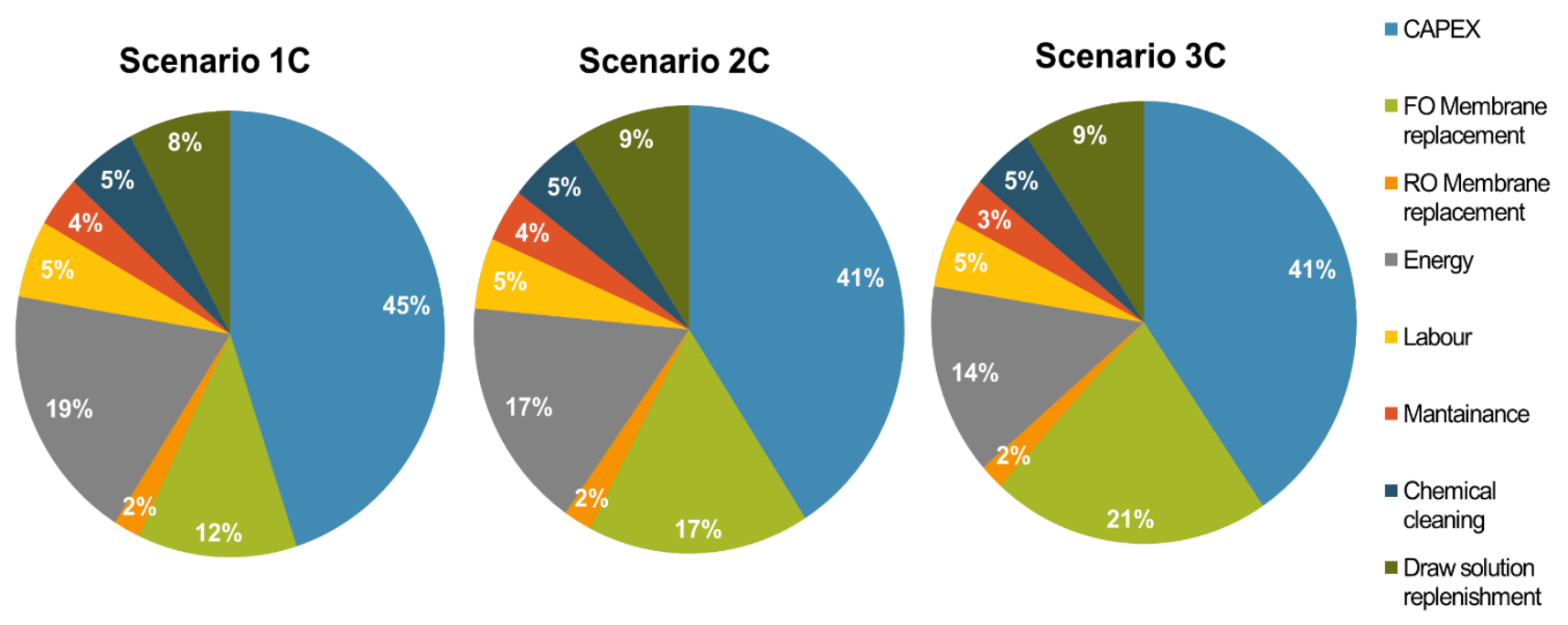

Figure 2. Water production costs. (a) Costs of the different FO-RO scenarios; (b) Cost distribution of closed-loop scheme (Scheme C) for the different FO recoveries, i.e. 50\%, 80\% and 90\%. 
(a)

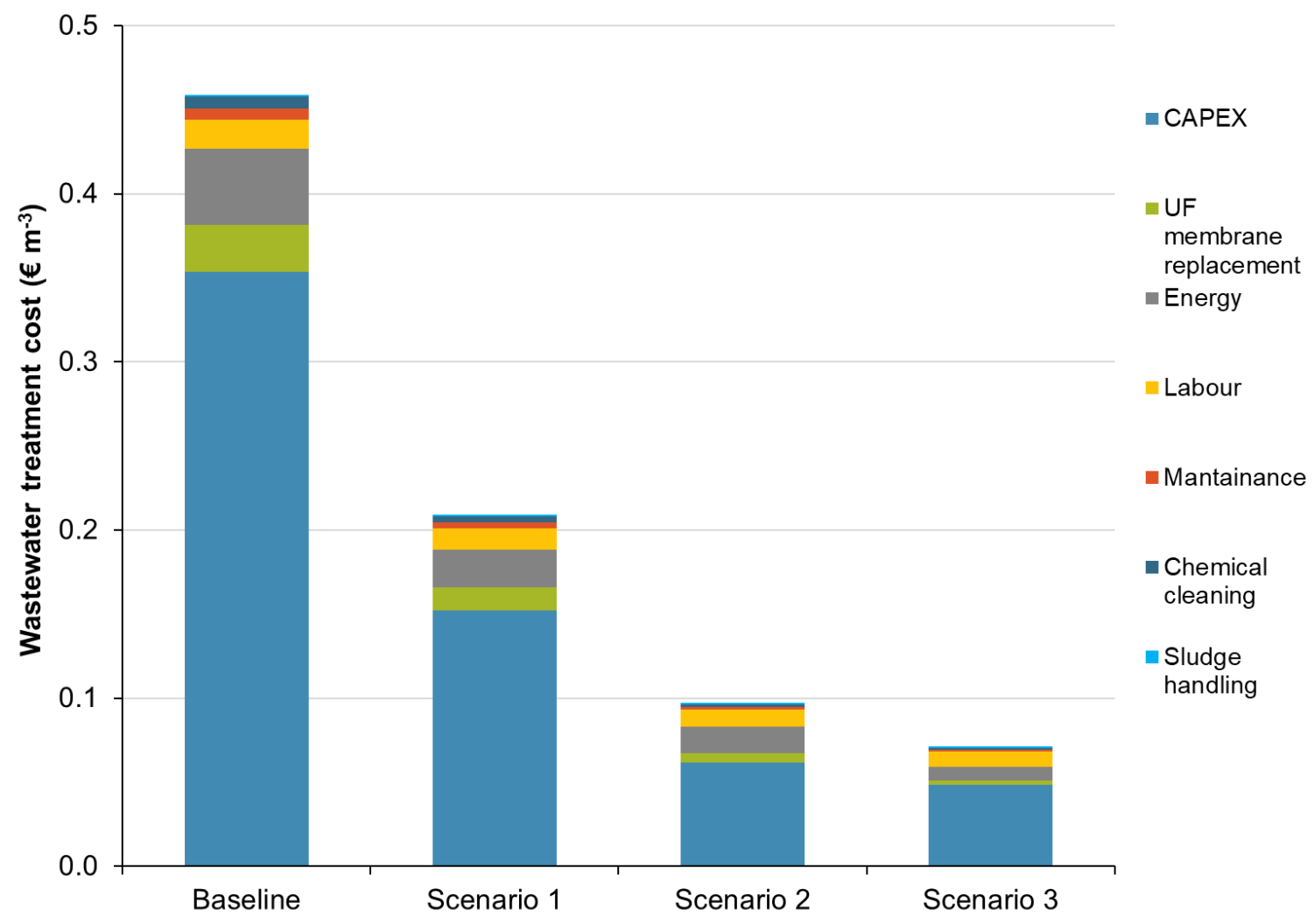

(b)

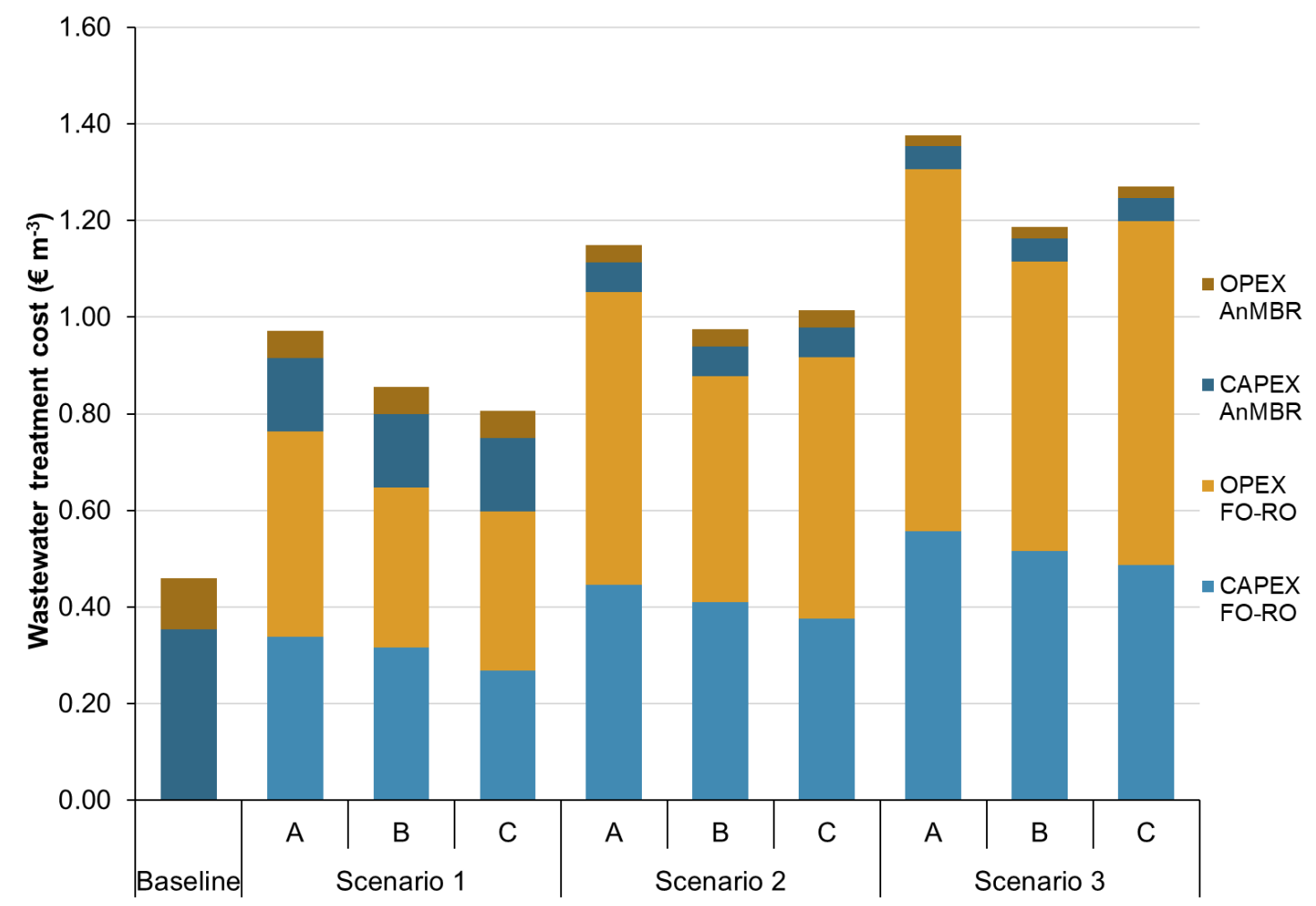

Figure 3. Wastewater treatment cost for an influent flow rate of $4440 \mathrm{~m}^{3} \mathrm{~d}^{-1}$. (a) AnMBR costs for the different FO scenarios. (b) FO-RO+AnMBR costs for the different scenarios. 


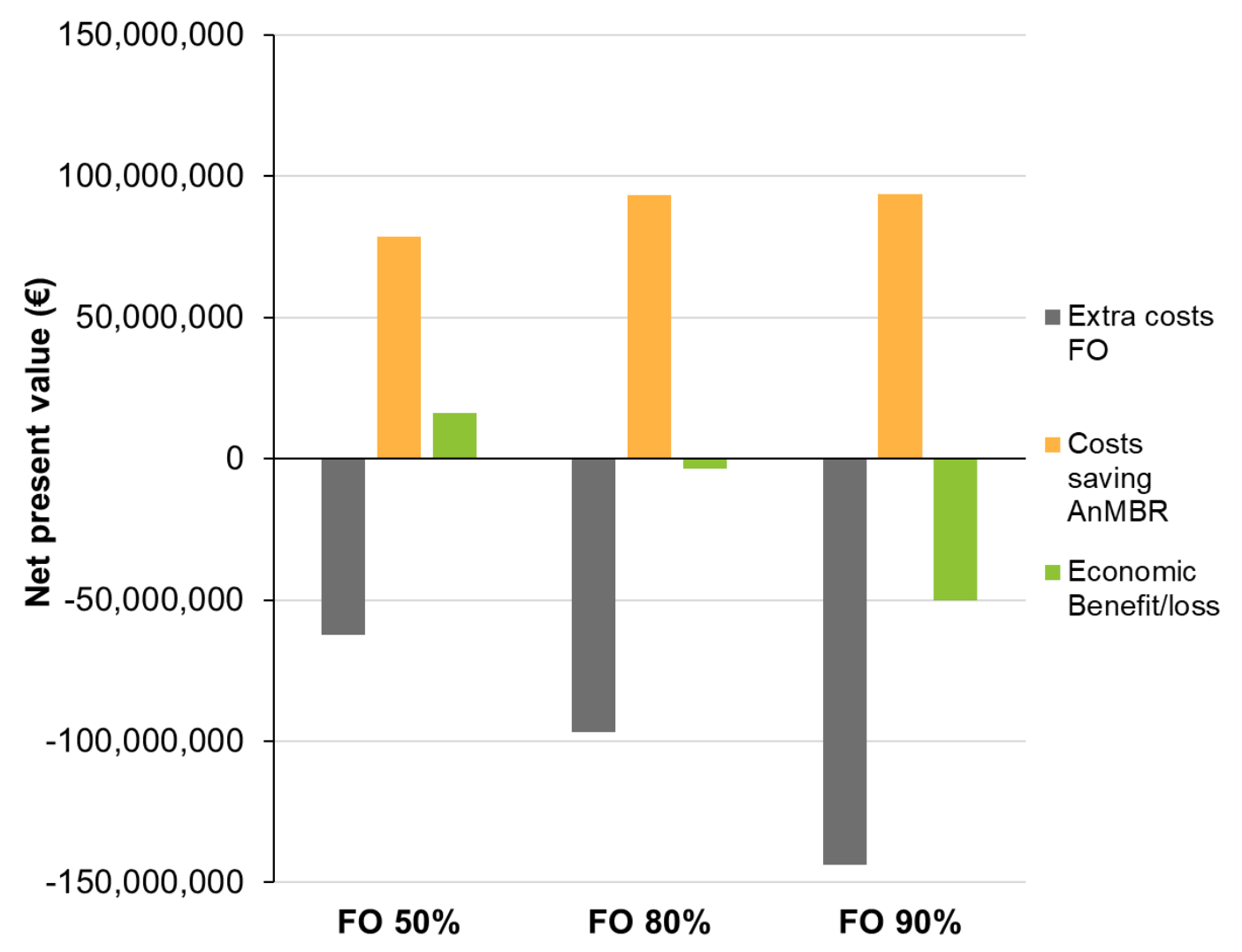

Figure 4. Economic evaluation of retrofitting SWRO plants to FO-RO+AnMBR plants. 


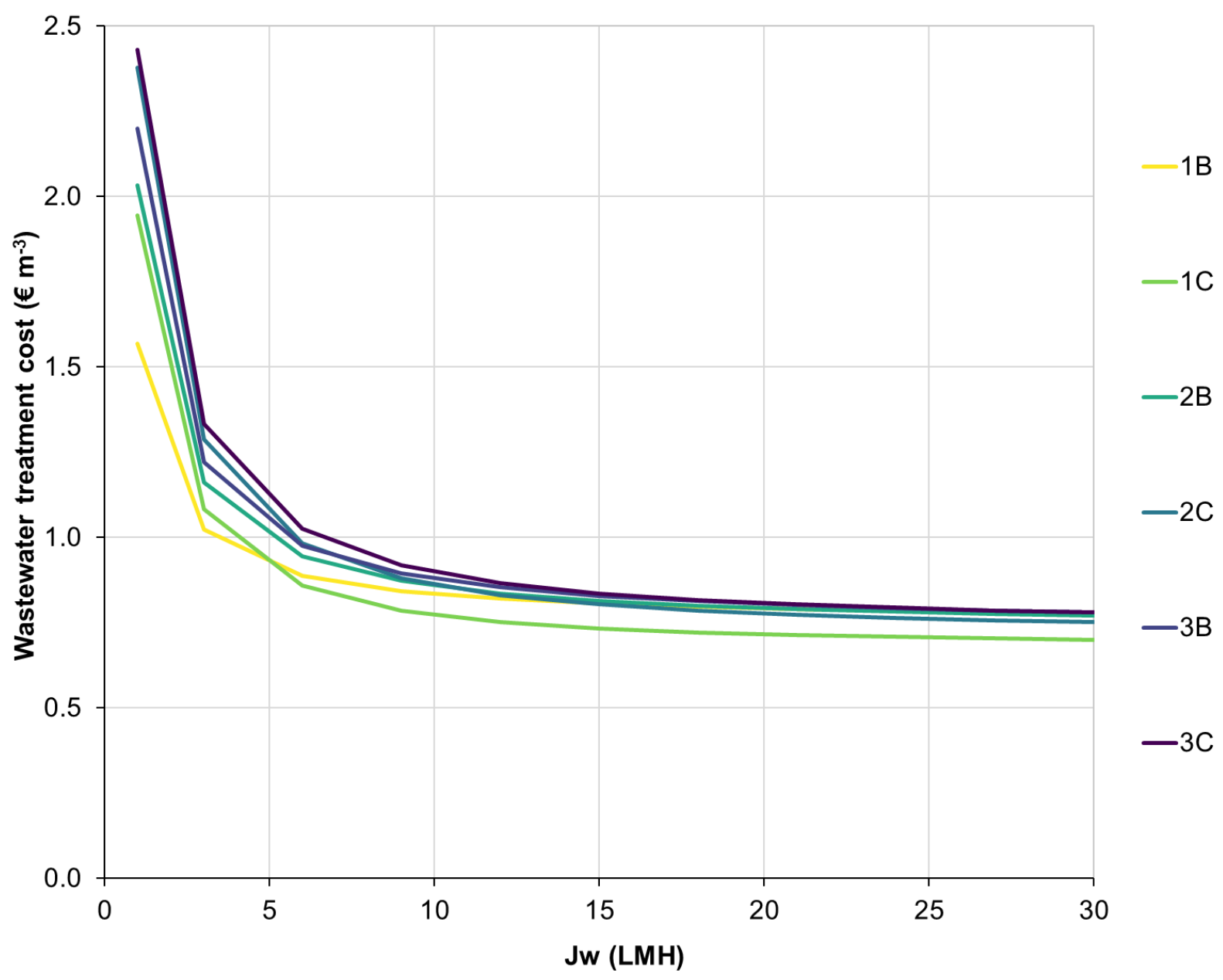

Figure 5. Sensitivity analysis of FO-RO+AnMBR cost in function to the FO membrane flux for Scheme B and C. Scheme A was not included since it displays the highest treatment cost. 